\title{
Кольская сверхглубокая скважина и рудообразующие системы Печенгского района
}

\author{
Лобанов К.В. ${ }^{1}$, Чичеров М.В. ${ }^{1}$, Шаров Н.В. ${ }^{2}$ \\ ${ }^{1}$ Институт геологии рудных месторождений, петрографии, минералогии и геохимии РАН, Москва, \\ lobanov@igem.ru \\ ${ }^{2}$ Институт геологии КарНЦ РАН, Петрозаводск, sharov@krc.karelia.ru
}

Аннотация. Кольская сверхглубокая скважина (СГ-3) - выдающееся достижение советской науки и техники, пробуренная в кристаллических породах Балтийского щита. СГ-3 пробурена с полным отбором керна и достигла глубины 12262 м, что позволило изучить глубинное строение земной коры и пересмотреть интерпретацию данных глубинных сейсмических исследований. Получены новые сведения по температурному градиенту, составу и физическим свойствам пород на глубоких горизонтах. Скважина вскрыла новые рудные тела медно-никелевых руд. Выявлены шесть типов рудной минерализация по всему разрезу скважины.

Ключевые слова: Кольская сверхглубокая скважина, глубинная структура земной коры, рудная минерализация.

\section{The Kola superdeep borehole and ore-forming systems of the Pechenga region}

\author{
Lobanov K.V. ${ }^{1}$, Chicherov M.V. ${ }^{1}$, Sharov N.V. ${ }^{2}$ \\ ${ }^{I}$ Institute of Geology of Ore Deposits, Petrography, Mineralogy and Geochemistry, RAS, Moscow, \\ lobanov@igem.ru \\ ${ }^{2}$ Institute of Geology Karelian Research Centre Russian Academy of Sciences, Petrozavodsk
}

\begin{abstract}
The Kola super deep borehole (SG-3) is an outstanding achievement of Soviet science and technology, it was drilled in the crystalline rocks as part of the Baltic Shield. SG-3 was drilled with full core sampling and reached a depth of $12262 \mathrm{~m}$, which allowed us to study the deep structure of the earth's crust and revise the interpretation of deep seismic data. New data on the temperature gradient, composition, and physical properties of rocks at deep horizons were obtained. SG-3 uncovered new ore bodies of copper-nickel ores. Six types of ore mineralization were identified throughout the borehole section.
\end{abstract}

Key words: Kola superdeep borehole, deep structure of the earth's crust, ore mineralization.

Кольская сверхглубокая скважина (СГ-3) задумывалась в качестве фундаментального научноисследовательского проекта, нацеленного на изучение недр Земли и процессов, идущих в них. Одна из основных задач бурения скважины заключалась в достижении гипотетического «базальтового» слоя земной коры (рис. 1).

Предположение, что континентальная кора состоит из верхнего «гранитного» и нижнего «базальтового» слоёв строилось на основе сейсмических данных, свидетельствующих об увеличении плотности горных пород с глубиной (Кольская сверхглубокая..., 1984).

СГ-3 была заложена в 1968 г. в северо-западной части Кольского полуострова, где развиты древнейшие на Земле рудоносные тектонические структуры раннего протерозоя и архея. Место заложения СГ-3 было выбрано Межведомственной комиссией для решения практической задачи по определению перспектив нижних горизонтов Печенгского рудного поля в отношении медноникелевых руд. К бурению этой скважины, проектная глубина которой составляла 15 километров, приступили 24 мая 1970 года, а к 1990 г. скважина должна была достигнуть глубины 13 км.

Целью бурения СГ-3 являлось изучение глубинного строения докембрийских структур Балтийского щита, типичных для фундамента древних платформ, и оценка их рудоносности. Основные задачи работ были следующие:

1. Изучить глубинное строение никеленосного Печенгского комплекса и архейского кристаллического основания Балтийского щита, выяснить особенности проявления на больших глубинах геологических процессов, включая процессы рудообразования. 

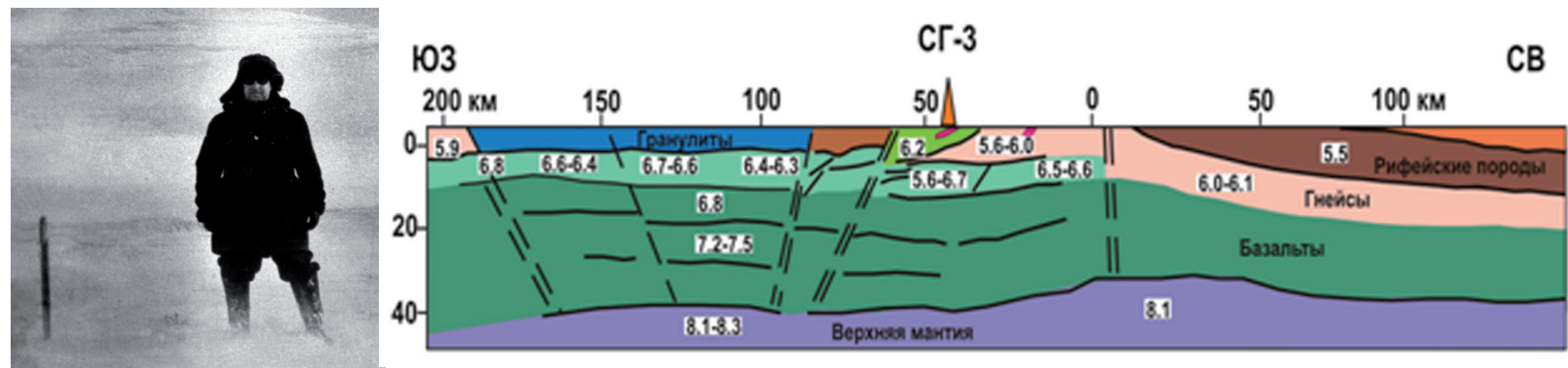

Рис. 1. Начальник Кольской ГРЭ Д.М.Губерман на месте заложения СГ-3. Сейсмический разрез континентальной земной коры по профилю Ловно-Печенга-Баренцево море, до бурения СГ-3.

Fig. 1. The head of the Kola GRE, D. M. Guberman, at the site of the SG-3 foundation. Seismic section of the continental crust along the profile of the North-Pechenga-Barents Sea, before drilling SG-3.

2. Выяснить геологическую природу сейсмических границ в континентальной земной коре и получить новые данные о тепловом режиме недр, глубинных водных растворах и газах.

3. Получить максимально полную информацию о вещественном составе горных пород и их физическом состоянии, вскрыть и изучить пограничную зону между «гранитным» и «базальтовым» слоями земной коры.

4. Усовершенствовать имеющиеся и создать новые технологии и технические средства для бурения и комплексных геофизических исследований сверхглубоких скважин.

На основании результатов глубинного сейсмического зондирования по профилю ЛовноПеченга-Баренцево море предполагалось, что под центральной и северо-восточной частями Печенгской структуры верхняя граница «базальтового» слоя находится на наименьшей глубине (Кольская сверхглубокая..., 1984). Скважина расположена на Северном крыле с таким расчетом, пересечь на отметке 4.7 км контакт раннепротерозойских вулканитов с архейскими гнейсами архейской серии, в интервале 7.5-8.5 км вскрыть поверхность Конрада и проникнуть внутрь «базальтового» слоя. По состоянию на 01.05.1991 г глубина скважины составляла 12262 м. Бурение осуществлялось с полным отбором керна. Результаты научного бурения во многом оказались неожиданными и заставили пересмотреть теоретические представления, которые до этого казались очевидными и незыблемыми (Кольская сверхглубокая..., 1998).

В реальности раннепротерозойские породы простирались до глубины 6842 м и только потом сменились архейскими гранито-гнейсами. Базальтовый слой вообще не был обнаружен - до самой рекордной глубины находятся архейские породы. Установлено, что уплотненные гранито-гнейсы при сейсмологических исследованиях воспринимались геофизиками в качестве более плотных, по сравнению со стандартными породами (рис. 2).
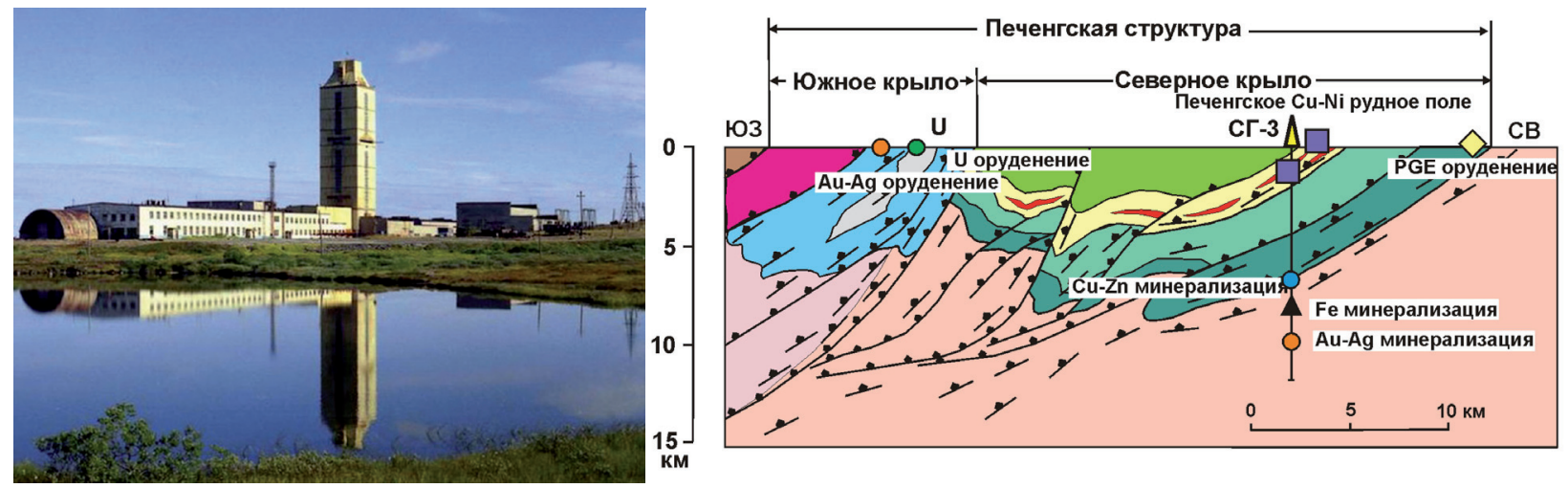

Рис. 2. Кольская сверхглубокая скважина. Схематический разрез интегральной геодинамической модели глубинного строения Печенгского рудного района через СГ-3 (Лобанов и др., 2010).

Fig. 2. Kola superdeep borehole. Schematic section of the integrated geodynamic model of the deep structure of the Pechenga ore region through SG-3. 
Интегральная глубинная модель, созданная на основе данных полученных при бурении Кольской сверхглубокой скважины, исследований на поверхности и глубинного сейсмического зондирования, рассматривает Печенгский рудный район как горизонтальный разрез мантийной вулканоплутонической рудообразующей системы центрального типа. Модель определяет северное крыло Печенгской структуры как фрагмент вулканической кальдеры, а ее южную часть описывает как чешуйчатую моноклиналь в сочетании с куполами реоморфических гранитоидов. Развитию системы предшествовал рифтинг консолидированной сиалической коры. Модель предполагает генетическую связь между протерозойским вулканизмом и никеленосным основным-ультраосновным плутонизмом. Основные и более молодые средние вулканические породы, заполняющие две вулкано-тектонические депрессии прослеживаются в мощной зоне северо-западных разломов. В дальнейшем вулкано-тектонические депрессии подверглись интенсивному сжатию и метаморфизму, что отразилось и на породах фундамента. Наконец, в условиях растяжения сформировались крутопадающие зоны катаклазитов и ретроградного метаморфизма (Лобанов и др., 2010).

Рудообразующие системы Печенгского рудного района известны крупными месторождениями медно-никелевых руд и месторождений и рудопроявлений $\mathrm{Pt}, \mathrm{U}, \mathrm{Au}, \mathrm{Pb}, \mathrm{Zn}$. Существуют три совмещенные системы: ЭПГ плутонические, $\mathrm{Cu}-\mathrm{Ni}$ вулканогенно-плутонические и U флюиднометасоматические руды, которые были сформированы при различных геотектонических условиях в карельском и свекофенском (2.4-1.6 млрд. лет) циклах. Процессы тектономагматической активизации, обусловленные формированием шельфа Баренцева моря, привели к трансформации этих рудных месторождений и формированию гидротермальной $\mathrm{Pb}-\mathrm{Zn}$ минерализации, $\mathrm{Au}-\mathrm{Ag}$ минерализации в СГ-3 и в южнопеченгской структурной зоне.

В разрезе СГ-3 рудная минерализация установлена на всем интервале в 12 км. В зависимости от сочетаний рудных элементов, форм их нахождения и минеральных парагенезисов в разрезе выделены шесть основных типов рудной минерализации: 1) сульфидная медно-никелевая и платинометальная, 2) сульфидная железная, 3) оксидная железная, 4) оксидная железо-титановая, 5) сульфидная медно-цинковая и 6) самородная золотая. Первые четыре типа сопоставимы с оруденением в протерозойской Печенгской структуре и ее архейском обрамлении по минеральному составу, характеру вмещающих пород и генезису (Лобанов и др.,2019) (рис. 3).

Возможно, это связано с повышенной тектонической активностью в глубинных горизонтах земной коры. В зонах циркуляции подземных вод, зафиксированных на больших глубинах (6.5-11.5 км и более), происходило отложение низкотемпературной гидротермальной минерализации (медной, медно-цинковой, никелевой).

Одним из важных результатов проходки Кольской сверхглубокой скважины явилось обнаружение в интервале 6-12 км зон дробления, трещиноватости и регрессивного дислокационного метаморфизма. Тектоническая природа зон регрессивного метаморфизма доказывается морфологическими признаками минерализованных трещин, а также перемещениями по типу сдвига разновозрастных жилок разного состава. Минералы амфиболитов и гнейсов в таких зонах замещаются хлоритом, актинолитом, эпидотом, карбонатом. Изредка в этих зонах проявляются пренит и пумпеллиит. Эти же минералы выполняют жилки и цемент микробрекчий. Следовательно, регрессивные изменения отвечают зеленосланцевой и пренит-пумпеллиитовой фациям (Козловский и др., 1988).

Наиболее распространенными рудными минералами сульфидной минерализации являются пирротин, пирит и халькопирит, ассоциирующие в прожилках с кварцем, карбонатом, хлоритом, пренитом, эпидотом и другими жильными минералами. Более редкие рудные минералы представлены сфалеритом, галенитом, борнитом, молибденитом, аргентопентландитом, зигенитом.

Минерализация установлена в зонах регрессивного дислокационного метаморфизма в интервале 6.2-12 км. Наряду с рассеянной вкрапленностью наиболее широко распространенных сульфидов - пирротина, пирита и халькопирита - она представлена хлорит-карбонат-кварцевыми прожилками, в которых наблюдаются более редкие и более разнообразные по составу сульфиды - сфалерит, галенит, борнит, молибденит, аргентопентландит, зигенит. В прожилках в метабазитах печенгской серии на глубине 6380 м встречается аргентопентландит, образующий мелкие выделения в халькопирите и реже в пирротине в ассоциации с пентландитом и сфалеритом. 


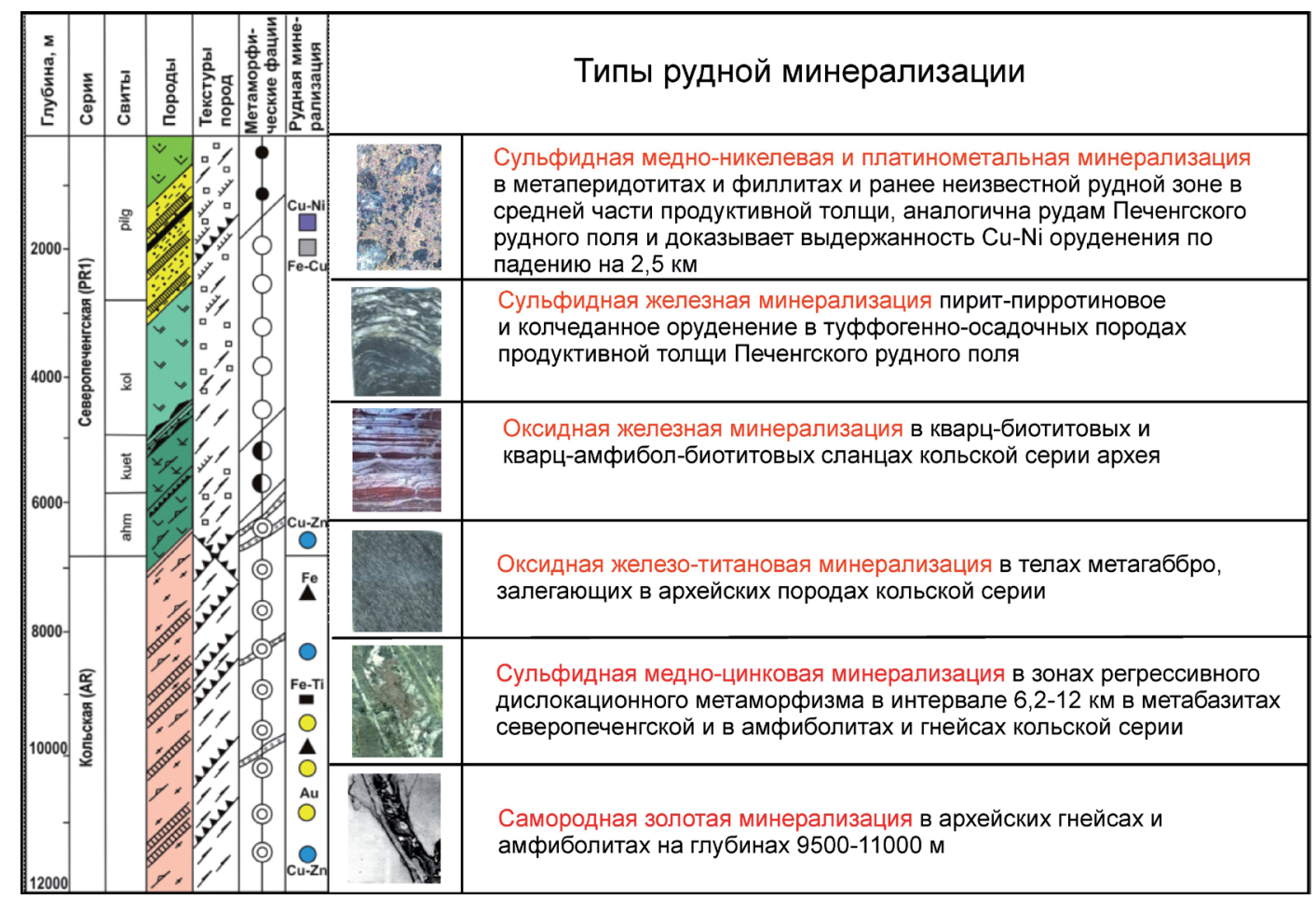

Рис. 3. Вертикальная рудная зональность в разрезе Кольской сверхглубокой скважины.

Fig. 3. Vertical ore zonality in the section of the Kola superdeep borehole.

Температуры образования гидротермальной сульфидной минерализации оценивались по распределению кобальта в срастаниях пирротина и пирита. Значения температур, вычисленные по коэффициенту распределения кобальта в этих сульфидах, в основном укладываются в интервале $184-323^{\circ} \mathrm{C}$, т. е. они существенно более низкие, чем температуры, характерные для амфиболитовой фации метаморфизма вмещающих пород.

Неожиданным результатом изучения СГ-3 стало открытие повышенных содержаний золота в интервале 9500-11000 м сложенном амфиболитами и гнейсами архейского возраста (2.6-2.8 млрд. лет), метаморфизованными в условиях амфиболитовой фации при $500-650^{\circ} \mathrm{C}$ и 3.5-6 кбар. Оно было обнаружено с помощью нейтронно-активационного анализа (ВНИИЯГГ), и подтверждено результатами минераграфических исследований (ИГЕМ). В интервале протяженностью 410 м содержания золота превышают 0.1 г/т, а местами достигают 1-6.7 г/т. В шлифах из керна обнаружены мельчайшие выделения самородного золота представленного (размером до 10 мкм) чешуйками и зернами неправильной формы в биотите, роговой обманке, плагиоклазе. Иногда чешуйки золота располагаются по спайности биотита. Золото не образует срастаний с другими рудными минералами и содержит до 26 \% серебра.

Верхняя граница золотоносного интервала совпадает с крупным разломом (9500-9700 м), который проявлен в керне скважины резким переходом от пологозалегающих биотит-амфиболитовых гнейсов к крутопадающим железистым кварцитам, горнблендитам, тальк-тремолит-флогопитовым сланцам и дайкообразному телу среднепротерозойских порфировидных гранитов лицко-арагубского комплекса (1.76 млрд. лет). Золотая минерализация пространственно совпадает с зонами регрессивных изменений, что говорит о ее структурном контроле (Лобанов и др., 2013).

Кольская сверхглубокая скважина - выдающееся достижение мировой и российской геологической науки в развитии континентального бурения. Она была пробурена в рамках программы «Изучение недр Земли и сверхглубокое бурение». Все работы по этой программе были осуществлены с применением только отечественной техники и технологии. Все оборудование для бурения было сделано на предприятиях оборонной промышленности СССР, также как при работе по проектам создания атомного оружия и космических кораблей. Была создана уникальная буровая установка «Уралмаш 15000». 
Впервые в мире СГ-3 была пробурена с применением новейших отечественных технических средств научного изучения глубинного строения земных недр. Были использованы новые материалы и технологии бурения, также создано уникальное буровое оборудование, позволяющее добраться до прежде недосягаемых глубин. Вот уже 50 лет этот результат остается непревзойденным. СГ-3 является прорывом в недра планеты Земля и может быть сопоставима только с полетом в космос.

Совместная работа около 200 ученых и специалистов из научных и производственных организаций различных министерств и ведомств позволила получить прямой вещественный материал и провести измерения различных параметров непосредственно в толще земной коры до глубины 12262 м с использованием нового научного оборудования, способного работать в условиях высоких температур и давлений. Полученные образцы горных пород с больших глубин по своему значению сопоставимы с образцами лунного грунта.

Геолого-геофизическая информация о глубинном строении Балтийского щита существенно скорректировала теоретические представления, господствовавшие до бурения скважины. На основании изучения минерально-геохимического состава пород керна и проведения комплекса исследований в стволе СГ-3 были получены данные о вещественном составе и физическом состоянии глубинных пород.

Геофизическая граница, дающая наибольшее отражение при сейсмическом зондировании, ранее считавшаяся зоной перехода пород «гранитного» слоя в более прочный «базальтовый слой», в разрезе СГ-3 проявлена менее прочными и менее плотными трещиноватыми породами - архейскими гнейсами. Вместо «поверхности Конрада» (кровля базальтового слоя) был выявлен субгоризонтальный «коровый волновод», своеобразная зона разуплотнения. Перемещение тектонических блоков по этим зонам обеспечило чешуйчато-надвиговое строение всего Лапландско-Печенгского блока.

Новые данные получены при оценке температур на больших глубинах. Предполагалось, что в гранито-гнейсовом фундаменте Балтийского щита температура с глубиной растет незначительно (примерно на $8-10^{\circ} \mathrm{C}$ на 1 км). Реальная температура в СГ-3 на глубине 10 км достигла $180^{\circ} \mathrm{C}$, а на глубине около 12 км $-212^{\circ} \mathrm{C}$, вместо ожидаемых $120^{\circ} \mathrm{C}$.

Принципиально новыми оказались и данные о процессе рудообразования в глубинных слоях земной коры. Так, на глубинах 9-12 км встретились высокопористые трещиноватые породы, насыщенные подземными сильно минерализованными водами. Эти воды - один из источников рудообразования. Раньше считали, что такое возможно лишь на значительно меньших глубинах.

Работа выполнена при финансовой поддержке РФФИ. Грант № 18-05-70001 «Изучение геологических и геодинамических обстановок формирования крупных месторождений стратегических металлов Арктической зоны России: выводы для прогнозирования и поисков новых месторождений».

\section{Литература}

1. Козловский Е.А., Губерман Д.М., Казанский В.И. Рудоносность глубинных зон древней континентальной земной коры (по материалам Кольской сверхглубокой скважины) // Советская геология. 1988. № 9. С. 3-11.

2. Кольская сверхглубокая. Исследование глубинной структуры континентальной коры бурением Кольской сверхглубокой скважины. Ред. Е.А. Козловский. М. Изд-во: Недра. 1984, 490 с.

3. Кольская сверхглубокая: Научные результаты и опыт исследований. Ред. Орлов В.П., Лаверов Н.П. М. Изд-во: МФ «ТЕХНОНЕФТЕГАЗ». 1998. 260 с.

4. Лобанов К.В., Казанский В.И., Кузнецов А.В., Жариков А.В. Интегральная геодинамическая модель Печенгского рудного района на основе корреляции геологических, петрологических и петрофизических данных по Кольской сверхглубокой скважине и опорному профилю на поверхности // Современные проблемы рудной геологии, петрологии, минералогии и геохимии. М. Изд-во: ИГЕМ РАН. 2010. C. $258-300$.

5. Лобанов К.В., Казанский В.И., Чичеров М.В. Золотая минерализация в разрезе Кольской сверхглубокой скважины и на поверхности в Печенгском рудном районе // Материалы международной конференции «Золото Фенноскандинавского щита». Петрозаводск. Изд-во: КНЦ РАН. 2013. С. 121-125.

6. Лобанов К.В., Чичеров М.В., Чижова И.А., Горностаева Т.А., Шаров Н.В. Глубинное строение и рудообразующие системы Печенгского рудного района (арктическая зона России) // Арктика: Экономика и Экология. 2019. № 3. С. 107-122. 